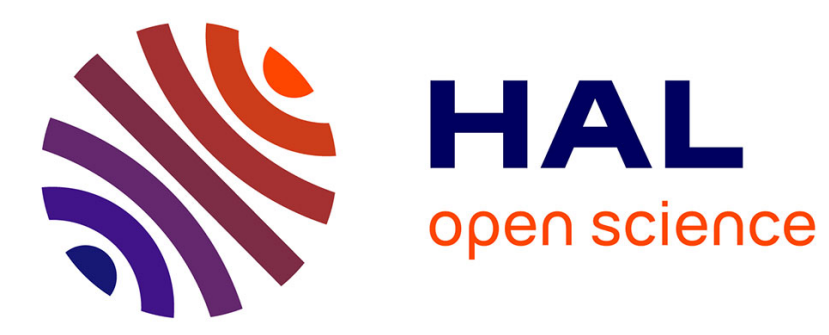

\title{
Thermoluminescence of a mixed rare earth phosphate powder La1-x-yCexTbyPO4
}

Philibert Iacconi, Michel Junker, Bernard Guilhot, Denis Huguenin

\section{To cite this version:}

Philibert Iacconi, Michel Junker, Bernard Guilhot, Denis Huguenin. Thermoluminescence of a mixed rare earth phosphate powder La1-x-yCexTbyPO4. Optical Materials, 2001, 17 (3), pp.409-414. 10.1016/S0925-3467(00)00104-X . emse-00527303

\section{HAL Id: emse-00527303 \\ https://hal-emse.ccsd.cnrs.fr/emse-00527303}

Submitted on 14 Nov 2010

HAL is a multi-disciplinary open access archive for the deposit and dissemination of scientific research documents, whether they are published or not. The documents may come from teaching and research institutions in France or abroad, or from public or private research centers.
L'archive ouverte pluridisciplinaire HAL, est destinée au dépôt et à la diffusion de documents scientifiques de niveau recherche, publiés ou non, émanant des établissements d'enseignement et de recherche français ou étrangers, des laboratoires publics ou privés. 


\title{
Thermoluminescence of a mixed rare earth phosphate powder $\mathrm{La}_{1}=x-y \mathrm{Ce}_{x} \mathrm{~Tb}_{y} \mathrm{PO}_{4}$
}

\section{Philibert IACCONI(1)*, Michel JUNKER ${ }^{(1,2)}$, BERNARD GUILHOT ${ }^{(2),}$ DENIS HUGUENIN ${ }^{(3)}$}

(1) Université de Nice-Sophia Antipolis, LPES, EA 1174, Parc Valrose, o61o8 Nice Cedex o2, France

(2) Ecole Nationale Supérieure des Mines de Saint Etienne, Centre SPIN ; Département PMMC ; CNRS-URA 2021, 158, Cours Fauriel ; 42023 Saint-Étienne Cedex 2, France

(3) IMRA, 220, rue A. Caquot. o6904 Sophia Antipolis Cedex, France

\begin{abstract}
The properties of thermoluminescence (TL) observed from various mixed rare earth (RE) phosphate powders $\mathrm{La}_{1-x-y} \mathrm{Ce}_{x} \mathrm{~Tb}_{y} \mathrm{PO}_{4}$ are reported. TL peaks appear around $-175^{\circ} \mathrm{C},-135^{\circ} \mathrm{C}$, $-80^{\circ} \mathrm{C},-35^{\circ} \mathrm{C}$ and $+25^{\circ} \mathrm{C}$ and the $\mathrm{TL}$ emission spectra of $\mathrm{La}_{1-x-y} \mathrm{Ce}_{x} \mathrm{~Tb}_{y} \mathrm{PO}_{4}$ are mainly composed of characteristic line transitions of $\mathrm{Tb}^{3+}$ ions. The results show that the co-doping with $\mathrm{Ce}^{3+}$ is not required to observe the TL emission of $\mathrm{Tb}^{3+}$. A model for the recombination mechanisms of the various TL peaks is discussed.
\end{abstract}

Keywords:

Rare earth phosphate; Thermoluminescence; Luminophors

PACS classification codes:

78.6o.Kn; 42.70. $-a$; 78.66.Nk

\section{Introduction}

When they are excited by the $253.7 \mathrm{~nm}$ radiation of a low pressure mercury lamp, the $\mathrm{La}_{1-x-y} \mathrm{Ce}_{x} \mathrm{~Tb}_{y} \mathrm{PO}_{4}$ powders emit a green luminescence [1 and 2] used as the green component in commercial trichromatic lamps. In fact, the spectral emission is composed of various lines of which the main, appearing at $544 \mathrm{~nm}$, is assigned to the ${ }^{5} \mathrm{D}_{4} \rightarrow 7 \mathrm{~F}_{5}$ transition of the $\mathrm{Tb}^{3+}$ ion [3]. The $\mathrm{Tb}^{3+}$ emission results from an energy transfer from $\mathrm{Ce}^{3+}$ to $\mathrm{Tb}^{3+}$ ions [1 and 2]. The transfer mechanism can be described in the following manner:

* Excitation of the $\mathrm{Ce}^{3+}$ ions into 5 d levels by an incident photon of wavelength $\lambda_{\text {exc }}\left(220<\lambda_{\text {exc }}<300 \mathrm{~nm}\right)$, then non-radiative deexcitation towards the lowest 5 d level followed by an energy transfer by diffusion towards neighbouring $\mathrm{Ce}^{3+}$ ions.

* Energy transfer from $\mathrm{Ce}^{3+}$ ion towards a neighbouring $\mathrm{Tb}^{3+}$ ion. The excitation into the $5 \mathrm{D}_{2}$ level is followed by radiationless transitions to the $5 \mathrm{D}_{3}$ and $5 \mathrm{D}_{4}$ levels, then radiative deexcitation of $\mathrm{Tb}^{3+}$ ions by relaxing to a $7 \mathrm{~F}_{J}(0<J<6)$ level.

The overall efficiency of the $\mathrm{Tb}^{3+}$ emission can be affected by the presence of lattice defects which are susceptible to:

1. absorb part of the exciting incident radiation,

2. absorb part of the emitted radiation,

\footnotetext{
* Corresponding author : $\underline{\text { iacconi@unice.fr }}$
} 
3. break the diffusion chain between the $\mathrm{Ce}^{3+}$ ions.

The aim of this work is to study the thermoluminescent properties of $\mathrm{La}_{1-x-y} \mathrm{Ce}_{x} \mathrm{~Tb}_{y} \mathrm{PO}_{4}$ mixed compounds in order to identify the role of such defects.

\section{Experimental conditions}

\section{II.1. Preparation of samples}

The products studied hereafter are obtained from $\mathrm{LaPO}_{4}, m \mathrm{H}_{2} \mathrm{O}$ and $\mathrm{La}_{1-x-y} \mathrm{Ce}_{x} \mathrm{~Tb}_{y} \mathrm{PO}_{4}, z \mathrm{H}_{2} \mathrm{O}$ precursors provided by Rhodia (France) and prepared by co-precipitation [4]. After drying and grinding, they are fired at $1250^{\circ} \mathrm{C}$, during $1 \mathrm{~h}$, under $\mathrm{N}_{2}$ atmosphere. At the end of this treatment, one obtains a powder characterised by a particle size in the $1-3 \mu \mathrm{m}$ range which obeys to the $\mathrm{La}_{0.57} \mathrm{Ce}_{0.29} \mathrm{~Tb}_{0.14} \mathrm{PO}_{4}$ formula. This compound is called LaCeT.

$\mathrm{La}_{1-x} \mathrm{Ce}_{x} \mathrm{PO}_{4}$ and $\mathrm{La}_{1-y} \mathrm{~Tb}_{y} \mathrm{PO}_{4}$ samples were obtained according to the same process: coprecipitation then firing at $1250^{\circ} \mathrm{C}$ during $1 \mathrm{~h}$ under $\mathrm{N}_{2}$ atmosphere. The values of $x$ and $y$ are the same as that for the LaCeT. So, the obtained powders are characterised by $\mathrm{La}_{0.71} \mathrm{Ce}_{0.29} \mathrm{PO}_{4}$ and $\mathrm{La}_{0.86} \mathrm{~Tb}_{0.14} \mathrm{PO}_{4}$ formulas.

\section{II.2. The experimental apparatus}

The thermoluminescence (TL) measurements were carried out in a secondary vacuum chamber from the liquid nitrogen temperature (LNT) to $350^{\circ} \mathrm{C}$. The sample, put down on a sample holder, was first cooled down at LNT and irradiated by X-rays (or by UV-mercury low pressure lamp). Then, it was heated up at the constant rate of $30 \mathrm{Kmin}^{-1}$. The TL curves were registered thank to an S13 response photomultiplier (Philips 2018B).

The irradiation was provided by a tungsten-target X-ray generator operating at $45 \mathrm{kV}, 2 \mathrm{~mA}$ with an air kerma rate of $0.035 \mathrm{~Gy} / \mathrm{min}$. Usually, the irradiation time was 10 min and the air kerma $0.35 \mathrm{~Gy}$.

The spectral analyses were obtained with $10-25 \mathrm{~nm}$ bandwidth interference filters and corrected to the spectral characteristics of the photomultiplier, filters and optical windows.

\section{Results}

\section{III.1. TL of LaCeT samples}

\section{III.1.1. Curves of TL}

After irradiation, at LNT, by the $253.7 \mathrm{~nm}$ of a mercury low pressure lamp, the LaCeT sample does not give any significant TL response.

On the other hand, the X-ray irradiation at LNT, gives rise to an intense TL phenomenon. As an example, we report the curve of TL observed for the LaCeT (Figure 1). The glow curve is characterised by an intense peak at $-80^{\circ} \mathrm{C}$ with two shoulders around $-135^{\circ} \mathrm{C}$ and $-35^{\circ} \mathrm{C}$ which indicate the presence of three types of trap defects existing in the LaCeT crystalline matrix. These results must be compared with those of Bourcet [1] who observed that, after irradiation at LNT with a radiation of wavelength $\lambda_{\text {exc }}=121 \mathrm{~nm}, \mathrm{La}_{0.35} \mathrm{Ce}_{0.60} \mathrm{~Tb}_{0.05} \mathrm{PO}_{4}$ sample presents one TL peak around $-145^{\circ} \mathrm{C}$ and who noted that this peak did not appear for irradiation with wavelength longer than $121 \mathrm{~nm}$.

\section{III.1.2. Spectral emissions of TL peaks}

The spectral analyses of each TL peak are reported in the Figure 2 (a). Between 450 and 600 $\mathrm{nm}$, one observes the characteristic line transitions of $\mathrm{Tb}^{3+}$ ions originating from the $\mathrm{5D}_{4}$ level, namely the $5 \mathrm{D}_{4} \rightarrow 7 \mathrm{~F}_{6,5,4}$ transitions which correspond, respectively, to 487,544 and $584 \mathrm{~nm}$. On the other hand, the emission spectra do not reveal any transitions from $5 \mathrm{D}_{3}$ level. This is due to the well-known effect of cross-relaxation which results of a resonant energy transfer between the transitions ${ }^{5} \mathrm{D}_{3} \rightarrow 5 \mathrm{D}_{4}$ and $7 \mathrm{~F}_{6} \rightarrow 7 \mathrm{~F}_{\mathrm{o}}$ of $\mathrm{Tb}^{3+}$ ions [5].

A broad band, very less intense than the $\mathrm{Tb}^{3+}$ emission lines, is also observed around 320$340 \mathrm{~nm}$. It is constituted of two components and is probably due to the $\mathrm{Ce}^{3^{+}}$ions. Bourcet [1] showed that the emission spectrum of $\mathrm{Ce}^{3+}$ ions, detected at $\mathrm{RT}$ in $\mathrm{La}_{0.35} \mathrm{Ce}_{0.6} \mathrm{~Tb}_{0.05} \mathrm{PO}_{4}$ samples, presents a broad band with two maxima at 315 and $335 \mathrm{~nm}$. 


\section{III.2. TL of $\mathrm{LaCePO}_{4}$ and $\mathrm{LaTbPO}_{4}$ compounds}

We studied also some samples with composition close to the one of LaCeT and in whom the chain of energy transfer from $\mathrm{Ce}$ to $\mathrm{Tb}$ does not exist. The TL curves of these products, which obey respectively to $\mathrm{La}_{0.71} \mathrm{Ce}_{0.29} \mathrm{PO}_{4}$ and $\mathrm{La}_{0.86} \mathrm{~Tb}_{0.14} \mathrm{PO}_{4}$ formulas, are presented in Figure 1. They were obtained in the same experimental conditions as that for LaCeT TL curve.

As expected, the emission of $\mathrm{Tb}^{3+}$ is found only in the product containing $\mathrm{Tb}^{3+}$ ions, namely $\mathrm{La}_{0.86} \mathrm{~Tb}_{0.14} \mathrm{PO}_{4}$ (Figure 2(b)).

Two TL peaks are observed around $-75^{\circ} \mathrm{C}$ and $+20^{\circ} \mathrm{C}$ (Figure $1(\mathrm{~b})$ ) with shoulders around $-125^{\circ} \mathrm{C}$ and $-35^{\circ} \mathrm{C}$ and exhibit emission spectra with spectral lines situated at 487,544 and $584 \mathrm{~nm}$ which correspond respectively to the transition $5^{5} \mathrm{D}_{4} \rightarrow \mathrm{F}_{4,5,6}$ of $\mathrm{Tb}^{3+}$. For its part, Bourcet [1] observed two TL peaks at $-100^{\circ} \mathrm{C}$ and $-53^{\circ} \mathrm{C}$ for the emission of $\mathrm{Tb}^{3+}$ in $\mathrm{La}_{0.95} \mathrm{~Tb}_{0.05} \mathrm{PO}_{4}$ irradiated by $121 \mathrm{~nm}$ radiation.

Moreover, the $320-340 \mathrm{~nm}$ emission is detected in the TL emission spectra of the $\mathrm{La}_{0.71} \mathrm{Ce}_{0.29} \mathrm{PO}_{4}$ compound (Figure 3 ). The TL curve of this sample is constituted of three peaks at $-175^{\circ} \mathrm{C},-135^{\circ} \mathrm{C}$ and $-40^{\circ} \mathrm{C}$ with a shoulder at $-10^{\circ} \mathrm{C}$ (Figure $1(\mathrm{a})$ ).

\section{Discussion and conclusion}

The mechanism of the fluorescence in LaCeT, is very well known. By exposure to $\lambda_{\mathrm{UV}}=\mathbf{2 5 3 . 7}$ $\mathrm{nm}, \mathrm{Ce}^{3+}$ ions are excited and transfer their energy to the $\mathrm{Tb}^{3+}$ species. As a result, the luminescence spectrum of LaCeT is principally composed by the $\mathrm{Tb}^{3+}$ emission [ 1 and 4$]$. In $\mathrm{TL}$, the problem is quite different. The exciting radiation is initially used to populate the trapping levels with the charge carriers released from the irradiation and the TL emission is then induced by an heating up which causes the detrapping of these charge carriers and their subsequent radiative recombination. So, the mechanism of TL emission is activated by thermal stimulation.

The TL curve of LaCeT obtained after X-ray irradiation at $-196^{\circ} \mathrm{C}$ is constituted of two peaks relatively intense at $-135^{\circ} \mathrm{C}$ and $-80^{\circ} \mathrm{C}$ with a weak shoulder around $-35^{\circ} \mathrm{C}$. The spectral distribution of the two main TL peaks is broken down into two kinds of emission. The one, characteristic of the $\mathrm{Tb}^{3+}$ ions, is composed of lines occurring from level $5 \mathrm{D}_{4}$ towards the levels ${ }^{7} \mathrm{~F}_{4,5,6}$; the other, very less intense, is observed around $320-340 \mathrm{~nm}$ and has been assigned to the transitions between the lowest $5 \mathrm{~d}$ level (likely ${ }^{5} \mathrm{D}_{3}[1]$ ) and the $4 \mathrm{f}$ levels ${ }^{2} \mathrm{~F}_{7 / 2}$ and ${ }^{2} \mathrm{~F}_{5 / 2}$ of $\mathrm{Ce}^{3+}$ ions.

Usually, the $5 \mathrm{~d} \rightarrow 4 \mathrm{f}$ transitions are very sensitive to the crystal field effects and the $\mathrm{Ce}^{3+}$ broad band emission might be shifted when the host crystalline matrix is changed. In $\mathrm{La}_{0.71} \mathrm{Ce}_{0.29} \mathrm{PO}_{4}$ and $\mathrm{La}_{0.57} \mathrm{Ce}_{0.29} \mathrm{~Tb}_{0.14} \mathrm{PO}_{4}$ compounds investigated in this work, the two components of $\mathrm{Ce}^{3+}$ emission appear approximately to the same wavelengths and correspond well to the results published by Bourcet [1] who analysed the emission of the $\mathrm{La}_{1-x-y} \mathrm{Ce}_{x} \mathrm{~Tb}_{y} \mathrm{PO}_{4}, \mathrm{La}_{1-x} \mathrm{Ce}_{x} \mathrm{PO}_{4}$ and $\mathrm{CePO}_{4}$ set (Table 1). This could have mean that the variation of the crystal field in $\mathrm{La}_{1-x-y} \mathrm{Ce}_{x} \mathrm{~Tb}_{y} \mathrm{PO}_{4}$ is weak when $x$ and $y$ vary or that optical properties of $\mathrm{Ce}^{3+}$ depend very feebly on the crystal field. This interpretation is corroborated by the data reported in Table 1 which gives the spectral characteristics of $\mathrm{Ce}^{3+}$ observed in various phosphate compounds. Generally speaking, two types of mechanisms can be suggested to explain the trivalent rare earth $\left(\mathrm{RE}^{3+}\right)$ emission observed in TL. They take into account either an energy transfer or a charge transfer process.

(1) In the first case, the mechanism of TL is entirely determined by the crystalline host matrix. Under ionising radiation, electron-hole pairs are created and trapped into the host lattice. Then, during the thermal stimulation, charge recombinations take place into the matrix and the energy released from the recombination is transferred to the $\mathrm{RE}^{3+}$ ions which emits their specific emission. The temperature of TL peaks depends solely on the host lattice traps whereas their spectral emission depends on the $\mathrm{RE}^{3+}$ ions. In this case, an overlap is required between the energy available from the host lattice and the RE electronic states; namely between the host lattice emission (HLE) and the $\mathrm{Ce}^{3+}\left(\right.$ orTb $\left.^{3+}\right)$ excitation. 
(2) In the second case, one considers that, under ionising radiation, the charge state of the RE is changed and that the released charge carriers are trapped in the crystalline matrix. Considering the electronic properties of ions such as $\mathrm{Ce}^{3+}$ or $\mathrm{Tb}^{3+}$, we think that during excitation process, they would have to act as electron donors following scheme (I)

$R E^{3+} \rightarrow R E^{4+}+e^{-}$

At the end of this excitation mechanism, the electrons $\mathrm{e}^{-}$remain trapped in the lattice.

Then, a thermal stimulation causes the release of the trapped electrons and their radiative recombination with $\mathrm{RE}^{4+}$ ions following scheme (II)

$$
R E^{4+}+e^{-} \rightarrow\left(R E^{3+}\right)^{*} \rightarrow R E^{3+}+h v_{R E}
$$

The emission arising from the heating up is characteristic of the involved $\mathrm{RE}^{3+}$ whereas the temperature of TL peaks depends also on the host lattice structure.

Another possibility, which can range in the field of charge transfer mechanisms, can be related to the eventual capacity of $\mathrm{Ce}^{3+}$ or $\mathrm{Tb}^{3+}$ ions to trap holes release (under ionising radiations) by the crystalline matrix. Following this assumption, the position of TL peaks observed during the subsequent heating up would be specific to the involved RE ions.

In the actual state of our investigations, we note that:

(i) five TL peaks are observed at around $-175^{\circ} \mathrm{C}$ (peak I), $-135^{\circ} \mathrm{C}$ (peak II), $-80^{\circ} \mathrm{C}$ (peak III), $-35^{\circ} \mathrm{C}$ (peak IV) and $+25^{\circ} \mathrm{C}$ (peak V);

(ii) only TL peaks II and IV appear on the three compounds investigated (LaCeT, $\mathrm{La}_{0.86} \mathrm{~Tb}_{0.14} \mathrm{PO}_{4}$ and $\mathrm{La}_{0.71} \mathrm{Ce}_{0.29} \mathrm{PO}_{4}$ ). They exhibit the $\mathrm{Tb}^{3+}$ (LaCeT and $\left.\mathrm{La}_{0.86} \mathrm{~Tb}_{0.14} \mathrm{PO}_{4}\right)$ or the $\mathrm{Ce}^{3+}\left(\mathrm{La}_{0.71} \mathrm{Ce}_{0.29} \mathrm{PO}_{4}\right)$ characteristic emission;

(iii) $\mathrm{LaCeT}$ and $\mathrm{La}_{0.86} \mathrm{~Tb}_{0.14} \mathrm{PO}_{4}$ have very similar TL properties (same TL curves with presence of peaks II-IV with $\mathrm{Tb}^{3+}$ emission);

(iv) peak III appears only in the $\mathrm{TL}$ curves of $\mathrm{LaPO}_{4}$ : $\mathrm{Tb}$ (namely $\mathrm{LaCeT}$ and $\mathrm{La}_{0.86} \mathrm{~Tb}_{0.14} \mathrm{PO}_{4}$ ) and is the main peak with $\mathrm{Tb}^{3+}$ emission (accompanied by a weak $\mathrm{Ce}^{3+}$ emission for LaCeT);

(v) peak I appears only in $\mathrm{La}_{0.71} \mathrm{Ce}_{0.29} \mathrm{PO}_{4}$ compound ( $\mathrm{Ce}^{3+}$ emission).

If we assume that the three investigated compounds can be considered as $\mathrm{LaPO}_{4}$ lattice-doped or co-doped by $\mathrm{Ce}, \mathrm{Tb}$ or $\mathrm{Ce}+\mathrm{Tb}$ elements and that the emissions of TL peaks of LaCeT are governed by an energy transfer mechanism (mechanism 1) from the host lattice to $\mathrm{Ce}^{3^{+}}$then to $\mathrm{Tb}^{+}$, we would have to observe similar TL curves for $\mathrm{La}_{0.71} \mathrm{Ce}_{0.29} \mathrm{PO}_{4}$ and $\mathrm{LaCeT}$ products. This is not the case because peak I, present in TL curve of $\mathrm{La}_{0.71} \mathrm{Ce}_{0.29} \mathrm{PO}_{4}$, is not observed in LaCeT compound (Figure 1) and because TL peak III, which appears in LaCeT compounds, is absent in $\mathrm{La}_{0.71} \mathrm{Ce}_{0.29} \mathrm{PO}_{4}$ sample.

Besides, the similarity of TL curves of Tb-doped $\mathrm{LaPO}_{4}\left(\mathrm{LaCeT}\right.$ and $\mathrm{La}_{0.86} \mathrm{~Tb}_{0.14} \mathrm{PO}_{4}$ ) encourages us to think that the presence of $\mathrm{Ce}^{3+}$ is not required to observe the $\mathrm{Tb}^{3+}$ emission in TL peaks II-IV of LaCeT.

We can equally reject the hypothesis of energy transfer between the host lattice and the $\mathrm{Ce}^{3^{+}}$ ions to interpret the presence of peak I. If this hypothesis was good, we would have to observe TL peak I in the LaCeT compound.

The emission of the main TL peaks of the LaCeT material does not seem to be interpreted by an "HLE $\rightarrow \mathrm{Ce}^{3+} \rightarrow \mathrm{Tb}^{3+}$ " energy transfer mechanism. So, the energy transfer mechanism between $\mathrm{Ce}^{3+}$ and $\mathrm{Tb}^{3+}$ as described by Bourcet [1] does not ensue the detrapping of charge carriers responsible for the various TL peaks of LaCeT.

Now, suppose that the hypothesis 2 applies. Under ionising radiation, electrons are released by $\mathrm{Ce}^{3+}$ as well as $\mathrm{Tb}^{3+}$ and trapped in different lattice sites. With regard to the TL properties of the compound studied, we can suppose that traps II and IV, common to the three products, 
are specific to the $\mathrm{LaPO}_{4}$ lattice. On the other hand, traps I and III are respectively associated to the $\mathrm{LaPO}_{4}$ :Ce and $\mathrm{LaPO}_{4}: \mathrm{Tb}$ (with or without Ce) lattices.

During the heating, the trapped electrons are released at specific temperature from the $\mathrm{LaPO}_{4}$ lattice and their recombination with the $\mathrm{Ce}^{4+}\left(\mathrm{La}_{0.71} \mathrm{Ce}_{0.29} \mathrm{PO}_{4}\right)$ or with the $\mathrm{Tb}^{+}$ions $\left(\mathrm{La}_{0.86} \mathrm{~Tb}_{0.14} \mathrm{PO}_{4}\right)$ occurs with characteristic emissions of these trivalent ions (scheme II). In the case of the LaCeT, the two ions Ce and $\mathrm{Tb}$ being present, the two characteristic emissions are observed and are probably obtained by disconnected recombinations $\mathrm{Ce}^{4+}+\mathrm{e}^{-}$and $\mathrm{Tb}^{4+}+\mathrm{e}^{-}$. In this last case, it is possible that a radiative energy transfer occurs from $\mathrm{Ce}^{3+}$ to $\mathrm{Tb}^{3+}$ ions.

As concluding remark, we note that all the TL peaks of LaCeT are situated at temperatures inferior to the working temperature of trichromatic lamps which is superior to room temperature. So, the observed TL phenomenon is not harmful to the application of LaCeT as green luminophors in such lamps because all the traps remain empty. In particular, the LaCeT luminophor induces no delay in the rising time of lighting and, reciprocally, no phosphorescence after the extinction of UV excitation.

\section{References}

[1] J.C. Bourcet, thèse d'Etat, Lyon, 1974.

[2] J.C. Bourcet, in: Proceedings of the 10th Rare Earth Research Conference, vol. 2, 1974, pp. $777-787$.

[3] J.P. Denis, thèse, Paris, 1972.

[4] M. Junker, thèse, Ecole Nationale Supérieure des Mines de Saint Etienne, 1995.

[5] J.A. Koningstein. Phys. Rev. 136A (1964), p. 717.

[6] H.S. Kiliaan, F.P. van Herwijnen and G. Blasse. J. Solid State Chem 74 (1988), p. 39.

[7] J.P. Briffaut and J.P. Denis. Phys. Stat. Sol 41 (1970), p. 781.

[8] A.M. Srivastava, M.T. Sobieraj, A. Valossis, S.K. Ruan and E. Banks. J. Electrochem. Soc 1379 (1990), p. 2959.

[9] B. Finke, L. Schwartz, P. Gürtler and M. Krass. Phys. Stat. Sol. (a) 130 (1992), p. K125.

[10] C. Parent, P. Bochu, G. Le Flem, P. Hagenmuller, J.C. Bourcet and F.J. Gaume-Mahn. Phys. Chem. Solids 451 (1984), p. 39 


\section{Figures}

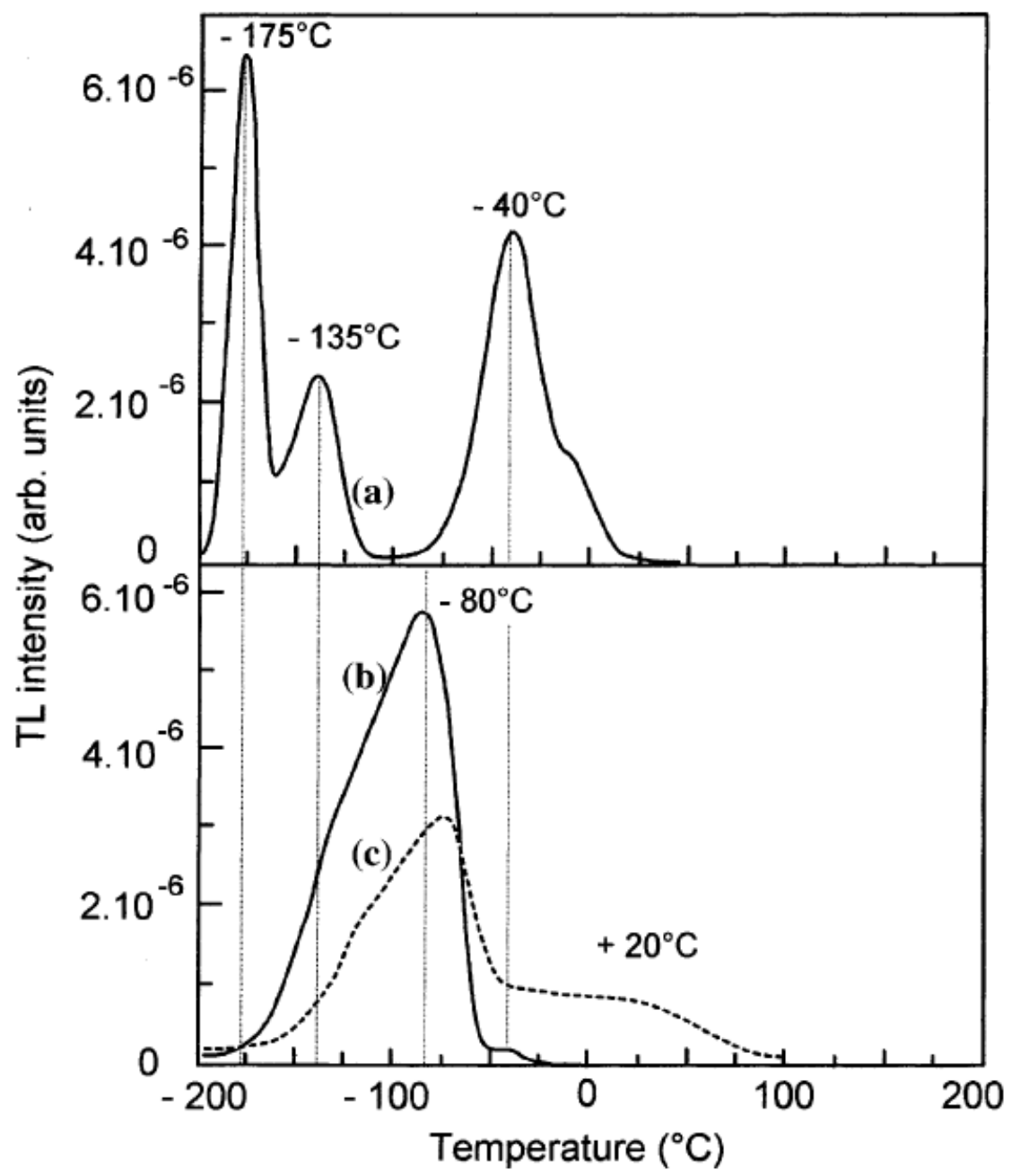

Figure 1: TL curve obtained from: (a) $\mathrm{La}_{0.71} \mathrm{Ce}_{0.29} \mathrm{PO}_{4}$; (b) LaCeT; and (c) $\mathrm{La}_{0.86} \mathrm{~Tb}_{0.14} \mathrm{PO}_{4}$ samples after X-ray irradiation at LNT (0.35 Gy). 


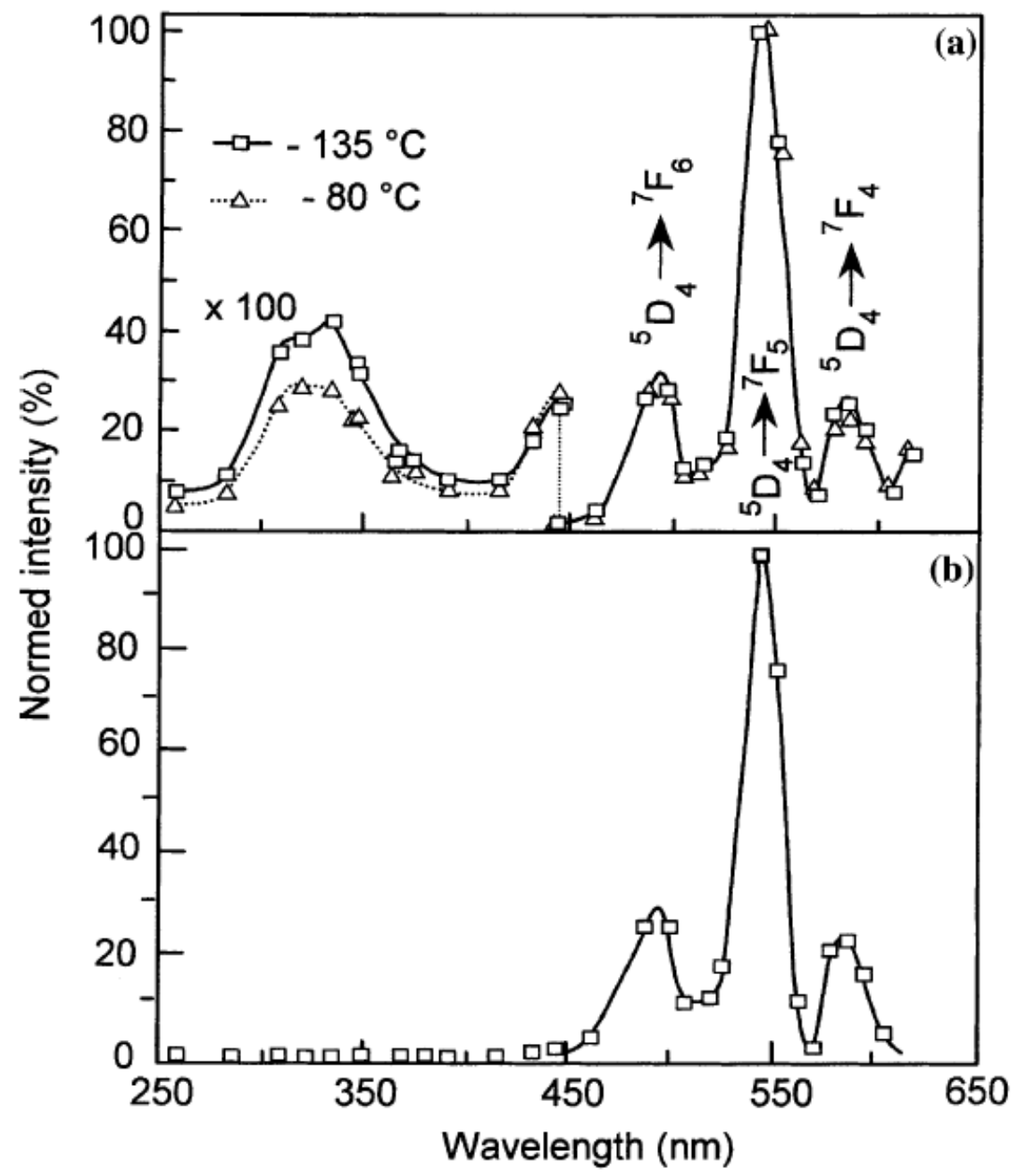

Figure 2: Spectral distribution of: (a) $-135^{\circ} \mathrm{C}$ and $-80^{\circ} \mathrm{C}$ TL peaks of LaCeT; and (b) $\mathrm{La}_{0.86} \mathrm{~Tb}_{\text {o.14 }} \mathrm{PO}_{4}$ samples obtained after X-ray irradiation at LNT ( $0.35 \mathrm{~Gy})$.

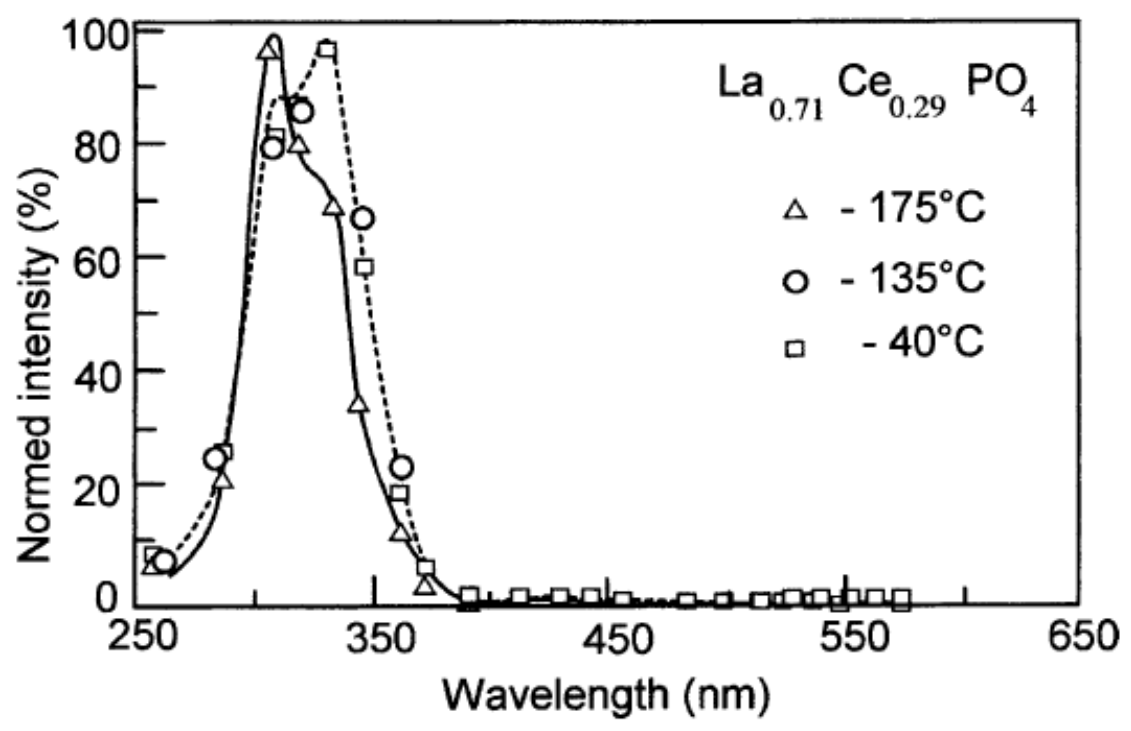

Figure 3: Spectral distribution of the three main TL peaks presented by $\mathrm{La}_{0.71} \mathrm{Ce}_{0.29} \mathrm{PO}_{4}$ after X-ray irradiation at LNT (o.35 Gy). 
Optical Materials, 2001, 17(3), 409-14, doi:10.1016/S0925-3467(oo)oo104-X

\section{Tables}

Table 1: Characteristics of the Ce $\mathrm{3}^{3+}$ emission observed by fluorescence in various mixed phosphate compounds ${ }^{(a)}$

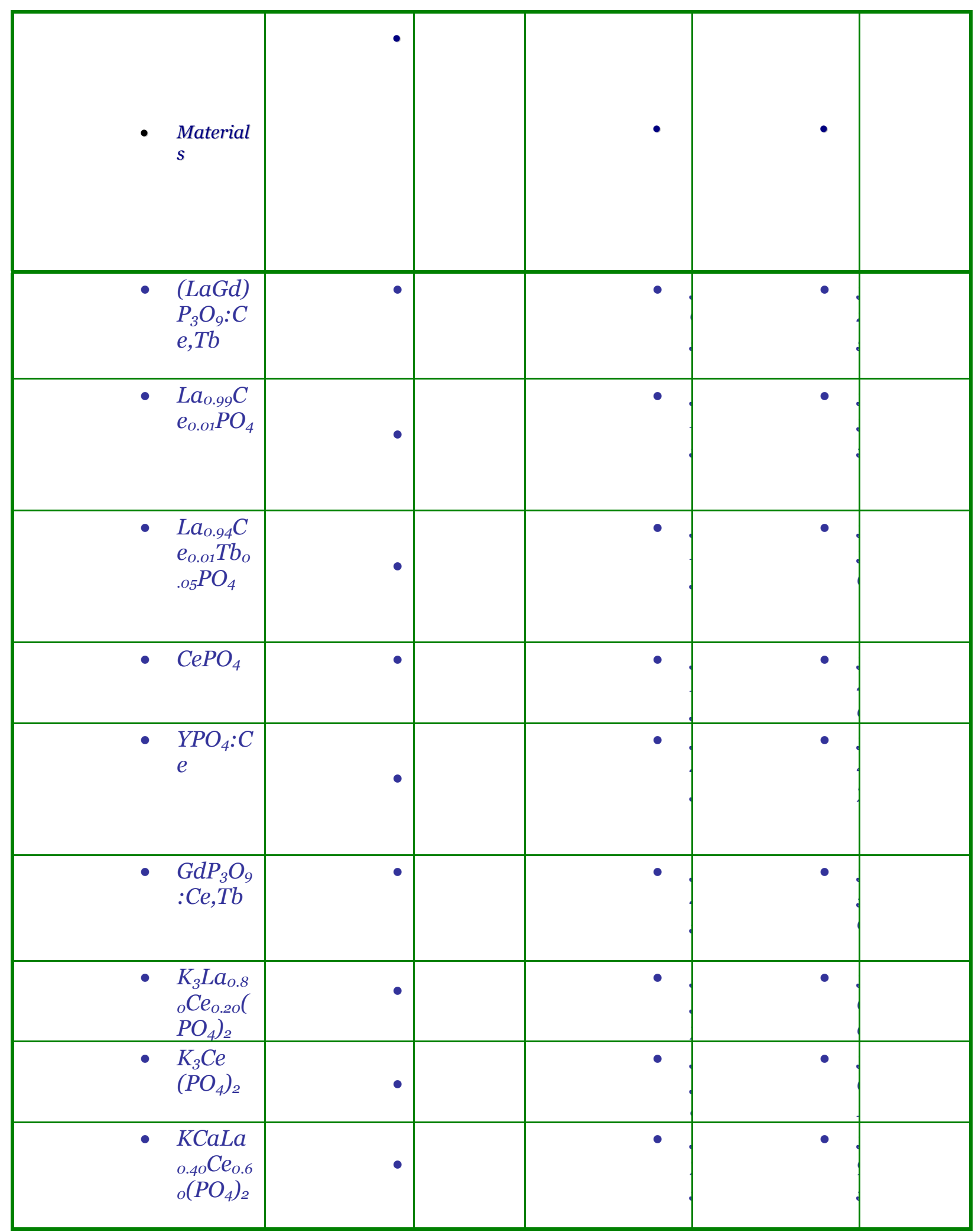

(a) RT: Room Temperature, LNT: .Liquid Nitrogen Temperature, LHeT: Liquid Helium Temperature 